\title{
Levels of Engagement in Task-based Synchronous Computer Mediated Interaction
}

\author{
Julio Torres \\ University of California Irvine \\ Íñigo Yanguas \\ University of San Diego
}

\begin{abstract}
Investigating task-based synchronous computer-mediated communication (SCMC) interaction has increasingly received scholarly attention. However, studies have focused on negotiation of meaning and the quantity, focus and resolution of language related episodes (LREs). This study aims to broaden our understanding of the role of audio, video, and text SCMC conditions by additionally examining second language (L2) learners' levels of engagement during the production of LREs as a result of interactive real-world tasks. We tested 52 dyads of L2 Spanish intermediate learners who completed a decisionmaking/writing task. Our main analysis revealed that dyads in the audio SCMC condition engaged in more limited LREs vis-à-vis the text SCMC group, and audio SCMC dyads also showed a trend of engaging more in elaborate LREs. The findings imply that interactive SCMC conditions can place differential demands on L2 learners, which has an effect on the ways in which L2 learners address LREs during task-based interaction.
\end{abstract}

\section{Résumé}

L'étude de l'interaction de communication synchrone par ordinateur (SCMC) basée sur des tâches a de plus en plus retenu l'attention des chercheurs. Cependant, les études se sont concentrées sur la négociation de la signification et la quantité, la concentration et la résolution des épisodes liés au langage (LRE). Cette étude vise à élargir notre compréhension du rôle des conditions SCMC audio, vidéo et texte en examinant en outre les niveaux d'engagement des apprenants de langue seconde (L2) lors de la production de LRE à la suite de tâches interactives du monde réel. Nous avons testé 52 dyades d'apprenants intermédiaires d'espagnol L2 qui ont terminé une tâche de prise de décision / d'écriture. Notre analyse principale a révélé que les dyades en condition audio SCMC s'engageaient dans des LRE plus limitées vis-à-vis du groupe SCMC textuel, et les dyades SCMC audio montraient également une tendance à s'engager davantage dans des LRE élaborés. Les résultats impliquent que les conditions SCMC interactives peuvent imposer des demandes différentielles aux apprenants de L2, ce qui a un effet sur la manière dont les apprenants de L2 abordent les LRE pendant l'interaction basée sur les tâches. 


\section{Levels of Engagement in Task-based Synchronous Computer-Mediated Interaction}

In cognitive-interactionist approaches to task-based language learning, theoretical and empirical efforts have been dedicated to investigating how task features (e.g., number of elements) and task conditions (e.g., interactive) drive second language (L2) learners' learning opportunities, language performance and development (e.g., Gilabert et al., 2009; Michel, 2011; Robinson, 2011; Skehan, 2009). Recently, though, Skehan (2016) convincingly argued that task conditions (and not task features) appear to be more consistently related to L2 learners' task performance and outcomes. Regarding task conditions, interactive synchronous computer-mediated communication (SCMC) task conditions, which include video, audio, and text modes, have increasingly received research attention (e.g., Jepson, 2005; Skyes, 2005; Yanguas, 2010, 2012; Yanguas and Bergin, 2018; Ziegler, 2015). This research surge is attributed to how the emergence of new technologies presents a new set of needs and target tasks (González-Lloret \& Ortega, 2014) as well as how the integration of social technologies in educational settings shape L2 instruction (e.g., Blake \& Guillén, 2020).

To date, most research efforts have been devoted to contrasting the effects between face-to-face and text SCMC conditions. Meta-analyses have shown that L2 development is also possible in text SCMC mode (Kang et al., 2019; Zielger, 2015). Further, with regards to learning opportunities (e.g., language related episodes) during peer interaction, differences can emerge between face-to-face and text SCMC conditions. For instance, evidence exists that language related episodes (LREs), which are instances in which learners chat about language issues while completing a meaning-oriented task, are significantly more prevalent in face-to-face peer interactions; whereas learners self-repair more often their non-targetlike utterances in text SCMC mode (e.g., Lai \& Zhao, 2006; Hamano-Buce, 2011; Rouhshad \& Storch, 2016; Torres \& Cung, 2019). TBLT researchers, however, have called for research to examine additional SCMC modalities such as audio and video to draw firm conclusions on the effects of task-based SCMC interactions (e.g., Yanguas, 2010; Ziegler, 2016). Examining the effects of task-based peer interactions in these SCMC modalities is critical to better understand how these task conditions may confer L2 learners with opportunities to engage with the L2 during the task execution process. That is, whether and how the differential demands placed by SCMC modalities contribute to learners' level of engagement during peer deliberations of linguistic forms. Therefore, grounded on the theoretical claims of the interactionist approach (e.g., Mackey, et al., 2012), the main goal of the current study is to expand this TBLT research strand by specifically investigating intermediate-level Spanish L2 learners' levels of engagement (i.e., elaborate, moderate, limited) during LREs while completing a real-world task across video, audio, and text SCMC modalities.

\section{Literature Review}

\section{Peer Interactions and Interaction Modes}

Since its inception, the interactionist hypothesis/approach has predicted that L2 learners' interactions with native speakers or more proficient interlocutors can have benefits for language development (e.g., Gass \& Mackey, 2020; Hatch, 1978; Loewen \& 
Sato, 2018; Long, 1981, 1996; Mackey et al., 2012; Pica, 1994). According to Mackey et al., this is due to a combination of features such as modified input, opportunities for output (i.e., production) and processing corrective feedback that draw learners' attention to their L2 linguistic system. Further, interactional moves that emerge from interactions such as LREs can provide L2 learners with learning opportunities to expand their L2 linguistic resources. Importantly, a few meta-analyses have supported the predictions of the interactionist approach in advancing L2 development (Keck et al., 2006; Mackey \& Goo, 2007; Russell \& Spada, 2006; Ziegler, 2015). Therefore, as characterized in the TBLT literature, the design of tasks as work plans that are primarily based on meaning with a communicative goal in which L2 learners rely mostly on their linguistic resources to reach a task outcome (e.g., Ellis \& Shintani, 2014; González-Lloret \& Ortega, 2014) can provide interaction opportunities for L2 learners. An example of a task that is commonly used in research and teaching is an information gap task (Ellis, 2018). In such a task, each L2 learner has a version of the same task with different information, which requires that learners provide each other with their piece of information to reach the task outcome. This type of task-based interaction, thereby, can lead to learning opportunities (e.g., LREs, corrective feedback) that are beneficial for L2 development.

Within task-based interaction research, one of the most researched areas is that between peers. Philp et al. (2014) characterized peer interaction as "any communicative activity carried out between learners, where there is minimal or no participation from the teacher" (p. 3). Peer interaction allows for learners to combine their linguistic and cognitive resources as well as to engage in hypothesis testing of linguistic forms to reach the communicative goals of a task (Philp, 2016). Much research has been dedicated to examining peer interaction, especially in face-to-face conditions. For instance, Sato and Lyster (2007) found that Japanese L2 learners of English were more at ease at hypothesis testing of linguistic forms with a peer rather than a native speaker. With regards to L2 development, Sato and Ballinger (2016) summarized that only a few studies have examined the role of peer interaction on L2 learning. The authors argued that these few studies imply that peer interaction can be beneficial for L2 learning, but that other interactional devices may be necessary such as corrective feedback and the production of modified output to advance L2 development. Furthermore, internal and external factors such as the modality of interaction (i.e., face-to-face, SCMC) can mediate the impact of peer interaction (Sato \& Ballinger, 2016).

Due to the advancement of social technologies in classroom settings that has enabled the use of digital platforms such as computer text chats (Blake \& Guillén, 2020; Elola \& Oskoz, 2017; Zheng et al., 2018), a need has emerged to address the efficacy of digital tools in promoting L2 learning opportunities and development (e.g., Thorne \& Reinhardt, 2008). From a cognitive-interactionist perspective, Ziegler (2015) conducted a meta-analysis of 14 primary studies contrasting the effects of interaction across face-toface and text SCMC conditions. The results overall demonstrated no significant differences between interaction in face-to-face and text SCMC conditions in promoting L2 development. However, a small advantage did emerge for text SCMC regarding written production measures, and an advantage for oral production measures was found in face-toface conditions. These results imply that a small advantage exists when the condition and assessment modalities match. Moreover, a recent meta-analysis by Kang et al. (2019) 
corroborated the findings from Ziegler that text SCMC conditions can lead to L2 development.

In further contrasts between face-to-face and text SCMC conditions, studies have also investigated the types of learning opportunities (e.g., LREs, self-repairs) that are triggered during peer interactions (for reviews, see Ortega, 2009; Sauro, 2011; Ziegler, 2016). The goal of these studies has been to ascertain whether text SCMC conditions can also lead to learning opportunities that can advance their interlanguage development. This is considering whether and how the chat log produced during text SCMC peer interactions provide distinct affordances and/or constraints that may affect peer interaction dynamics. According to Ziegler (2015), chat logs provide a written record that enables L2 learners to have more time to review content and notice target forms for further processing. In sum, these studies have revealed that learning opportunities emerge in both face-to-face and text SCMC conditions (e.g., Blake, 2000; Lee, 2001; González-Lloret, 2003). However, interaction modality can affect the quantity and quality of these interactional moves. For instance, an observation from these studies is that learners trigger more LRE episodes during face-to-face interaction, but self-repair (i.e., learners self-initiate a modification of a previous utterance) more non-targetlike utterances in text SCMC conditions (e.g., Lai \& Zhao, 2006; Hamano-Bunce, 2011; Loewen \& Wolff, 2016; Rouhshad \& Storch, 2016; Torres \& Cung, 2019). Therefore, given the inherent characteristics of SCMC, SCMC mode can mediate the types of learning opportunities and interactional moves that L2 learners engage with during peer interactions.

\section{Video, Audio and Text SCMC Task Conditions}

While empirical advances on the contrasting effects of face-to-face and text SCMC conditions have taken place in the field, little is still known about the effects of different SCMC modalities (i.e., video, audio) on learning opportunities such as LREs. This is a critical area to understand given the rise of video- and audio-based digital technologies that have amplified SCMC options in L2 learning environments. Of relevance also is the recent world events dealing with Covid-19 that have forced foreign/second language educators to teach remotely using digital platforms such as zoom or google classrooms (GonzálezLloret, 2020). As González-Lloret argued, educators ought to still design instruction that aligns with evidence-based pedagogical practices to create an optimal virtual environment for L2 learning to occur. Given this context, González-Lloret provided sample technologymediated tasks to promote collaboration among students. Therefore, empirical studies that shed light on how SCMC modalities mediate task-based peer interaction dynamics are necessary to provide guidance in designing collaborative virtual tasks when using these different digital platforms.

To address this issue, studies have begun to examine how peer interactions across different SCMC modalities have an effect on interactional moves such as negotiation of meaning, LREs and repair episodes as well as lexical and pragmatic development. With regards to negotiation of meaning and repair moves, Jepson (2005) investigated 10 groups of L2 English learners' negotiated interactions, which included clarification requests (e.g., What do you mean by X?), confirmation checks (e.g., Did you mean/say X?) and comprehension checks (e.g., Do you understand?), as well as repair moves (e.g., selfrepairs) in text and audio SCMC. Jepson (2005) found that both types of interactional 
moves emerged in both SCMC modalities, but with much more frequency in audio SCMC. Further, audio SCMC was effective to address participants' pronunciation breakdowns during peer interaction. In another study, Yanguas (2010) examined negotiation of meaning episodes (e.g., comprehension checks) that resulted from task-based peer interactions among 15 dyads of intermediate-level Spanish L2 learners. The dyads were randomly assigned to complete a jigsaw task in face-to-face, video or audio SCMC condition. Though Yangua's results revealed that dyads in the three SCMC conditions mostly focused on lexical items during interaction, a slightly higher percentage of negotiation of meaning episodes $(57 \%)$ occurred in the audio SCMC condition but a rather equal percentage of episodes in face-to-face $(50 \%)$ and video SCMC (48\%). Yanguas also analyzed whether peers achieved complete or partial understanding of lexical items because of negotiation of meaning episodes. The findings indicated that participants in the audio SCMC condition achieved a complete understanding of novel lexical items to a lesser extent (45\%) than the face-to-face (70\%) and video SCMC (64\%) groups.

Yanguas (2012) reported on L2 Spanish lexical development through production, recognition and listening comprehension tests with the same group of intermediate-level learners, task conditions (face-to-face, audio and video SCMC) and jigsaw task as in Yanguas (2010). Regardless of task condition, the findings revealed that learners were able to significantly produce and recognize more L2 target lexical items immediately after their peer execution of the jigsaw task. Unlike for production abilities, though, participants' ability to recognize L2 target lexical items was retained approximately two weeks (i.e., delayed testing) after task-based intervention. A significant decrease was also found in participants' listening comprehension abilities at delayed testing. However, participants in the audio SCMC condition significantly outperformed the other two groups in the number of L2 target lexical items that they still comprehended. In a study that examined L2 pragmatic development across face-to-face as well as text and audio SCMC conditions, Sykes (2005) examined intermediate-level L2 Spanish learners' development of speech acts that involved refusals of an invitation. Sykes reported that all groups improved their pragmatic competence aligning more closely with Spanish native speakers' use of speech acts to refuse an invitation. However, differences with regards to pragmatic strategies did emerge across the three conditions. For example, participants in the text SCMC condition produced more complex and varied strategies given lower time pressure and the need to be more explicit about their communication, which was not the case for face-to-face and audio conditions. The participants in the audio condition added more complex grounders (i.e., explanations for not attending an event) as their speech acts, whereas the face-to-face dyads utilized more supporting moves (e.g., apologies) to refuse an invitation.

Recently, and more in line with the goal of the current study, Yanguas and Bergin (2018) investigated intermediate-level Spanish L2 learners' quantity, focus and outcomes of LREs resulting from task-based peer interaction across video and audio SCMC conditions through Skype as well as task type (i.e., jigsaw, dictogloss). In sum, task condition and task type did not influence the quantity of LREs generated during peer interaction. However, task type did have an impact on lexical and grammatical foci of LREs, with more lexical LREs triggered during the execution of the jigsaw task, and more grammatical LRE episodes for the dictogloss task. With regards to LRE outcomes, an analysis of whether questions pertaining to language use were correctly, incorrectly, or not addressed revealed that peer interactions in the audio SCMC condition resulted in a 
significantly higher number of unresolved LREs. This finding implies that dyads in the audio SCMC condition were not as concerned with addressing LREs triggered by their interaction partner.

The preceding literature on the contrasting effects of SCMC modalities indicates that language development (e.g., lexical, pragmatic) and learning opportunities (e.g., LREs) are possible across text, audio, and video SCMC conditions. That is, the benefits of interaction as posited by the interactionist approach (Mackey et al., 2012) can be extended to SCMC environments. Nevertheless, a closer analysis of the findings across SCMC conditions also point to differential linguistic behaviour among L2 learner dyads resulting from the nature of such conditions. Based on the available evidence thus far, an emerging pattern signals that it is peer interactions in the audio SCMC condition that leads to the most variation in L2 linguistic behaviour. Positive benefits of audio SCMC seem to include the production of a higher number of negotiation of meaning episodes, the noticing of breakdowns in pronunciation, and the retention of listening comprehension of novel lexical items. Conversely, a couple of limitations are a higher number of unresolved LREs and not achieving a complete understanding of the meaning of novel lexical items through interactional moves such as comprehension checks. To account for the effects of the audio SCMC condition, Yanguas (2012) argued that a salient feature of audio SCMC is the lack of visual cues that can provide extralinguistic information during peer interaction. Yanguas also endorsed the claim by Mayer's (2005) cognitive theory of multimedia that humans process visual and auditory information through different channels. Potentially, then, the lack of visual support and a greater reliance on linguistic information in audio SCMC can direct L2 learners' cognitive resources in different ways.

Therefore, to expand the scope of this strand of task-based research, the current study aims to further address the effects of text, audio, and video SCMC conditions on task-based peer interactions. Given the findings of the previous studies, a goal here is to provide additional empirical evidence to confirm and extend the emerging patterns observed in audio SCMC. The current study builds on Yanguas and Bergin's (2018) study in that the researchers examined intermediate-level Spanish L2 learners' engagement with LREs during task execution. In the current study, we also examined intermediate-level Spanish learners as well as LREs with regards to quantity, focus and outcomes, but our study expanded the research design in the following ways: (1) we used a real-world task rather than pedagogic tasks (e.g., jigsaw, dictogloss); (2) we included a text SCMC group; and (3) we analyzed dyad's levels of engagement during LRE episodes. In what follows, we provide an overview of the literature on LREs and levels of engagement.

\section{Language Related Episodes and Levels of Engagement}

Language related episodes or LREs can be characterized as interactional moves that emerge from meaning-based interactions in which L2 learners engage in dialogue to tackle questions about language forms (e.g., Swain \& Lapkin, 1995; Williams, 1999). Questions regarding language forms can focus on lexical (e.g., how do you say "budget" in Spanish?), grammatical (e.g., what is the past tense of "to go"?) and spelling (e.g., how do you spell "obnoxious"?) items among others. After the initiation of an LRE, three options can follow depending on whether and how the LRE gets addressed. That is, it is quite possible that the interlocutors do not address the LRE at all and proceed on with 
completing the task. Ideally, though, the interlocutors will address the LRE correctly in a targetlike fashion, but a possibility also exists in which the LRE is incorrectly addressed. Whether or not LREs are correctly resolved can depend on several factors such as L2 learners' proficiency levels (e.g., Kim \& McDonough, 2008), task type (e.g., Abadikhah, 2011), task mode (e.g., Niu, 2009) and even type of dyadic interaction (e.g., Storch, 2002). Critically, some evidence exists that L2 learners' involvement with LREs during peer interaction can lead to language development (e.g., Fernández Dobao, 2016; Henshaw, 2015; Kim, 2008).

Due to the potential learning benefits resulting from involvement with LREs, recent work has sought to investigate whether learners' extensive or limited deliberation of language forms during LREs should be a variable to consider in L2 development (e.g., Rouhshad \& Storch, 2016). This is referred to as levels of engagement which can include elaborate and limited levels of engagement. In describing levels of engagement, Storch (2008) argued that LREs can differ with regards to the length to which L2 learners invest attention to language forms ranging from a couple to multiple conversation turns. Elaborate LREs consist of multiple conversation turns in which L2 learners engage in providing explanations and alternatives to address the LRE, whereas simply stating a linguistic form to address the LRE without any explanations or alternatives is considered a limited LRE. Storch's (2008) study with L2 English learners completing a dyadic text reconstruction activity established that those dyads who engaged in elaborate LREs demonstrated more retention of the target structures that were addressed than those in limited LREs. Relevant to the current study, Rouhshad and Storch (2016) analyzed L2 peers' LRE levels of engagement across face-to-face and text SCMC modes. In line with previous studies, more LREs were generated in the face-to-face condition, but a novel finding was that peer interactions in the text SCMC condition were mostly limited. That is, the text SCMC condition was not conducive to L2 learners' substantial engagement with language forms during LREs. To extend this area of inquiry, therefore, the current study examined LREs in conjunction with levels of engagement across video and audio SCMC modalities. As such, the aim of this study is to further elucidate the role of SCMC conditions on L2 learners' initiations, resolutions, and deliberations of LREs during task-based peer interactions.

\section{The Current Study}

The previous section raised the need to examine whether and how the nature of different SCMC modalities (i.e., video, audio, text) can prompt L2 learners' engagement during dialogues about language forms while completing a meaning-oriented task. Specifically, the current study addresses the quantity, focus and resolution of LREs as well as peers' levels of engagement during LRE deliberations. Therefore, to address these issues, the current study posits the following two research questions:

1. Is there an effect of SCMC mode (video, audio, text) on the quantity, focus and resolution of LREs during task-based peer interaction?

2. Is there an effect of SCMC mode (video, audio, text) on LRE levels of engagement during task-based peer interaction? 
For the first research question, based on previous studies, we hypothesized that task-based peer interactions in the audio SCMC condition will lead to a higher number of unresolved LREs. Also, the text SCMC condition will lead to a lower number of initiated LREs in comparison to the other two conditions. No differences will emerge with regards to foci of LREs across the SCMC conditions. For the second research question, we assumed a null hypothesis.

\section{Method}

\section{Participants}

Participants in this study $(N=104)$ were enrolled in six intact intermediate Spanish classes at two institutions of higher education in Southern California. Students in these classes have completed or demonstrated knowledge equivalent to 1.5 years of college Spanish. Participants were randomly assigned to three different groups, which led to the formation of random dyads. The groups consisted of 19 dyads in the video SCMC group (VidSCMC), 16 dyads in the audio SCMC group (AudSCMC), and 17 dyads in the textbased chat SCMC group (TxtSCMC). As it can be seen in Table 1, the average age of our total participant pool was $19.3(S D=1.6)$, and most of our participants were female $(N=$ 82). We elicited participants' self-reports on the percentage of their overall daily use of English and Spanish and found an average of 49.2\% $(S D=3.2)$ for English use and 4.2\% (3.2) for Spanish use. Importantly, the dyads across the three conditions did not differ with regards to age as well as percentage of daily English and Spanish use.

Additionally, we gathered information to estimate participants' proficiency in Spanish as well as their language dominance to ensure comparable groups across conditions and institutions. To examine Spanish proficiency, participants completed Ortega's (2000) Elicited Imitation Task (EIT) in which participants had to repeat after a two-second pause 30 Spanish sentences that increased in syntactic complexity (see also Bowden, 2016). The overall group average was $66.1(S D=19.3)$, with a mean score of 60.8 $(S D=20.8)$ for the AudSCMC group, $70.2(S D=18.6)$ for the VidSCMC group and 67.8 $(S D=15.0)$ for the TxtSCMC group. No significant differences were found in EIT scores by SCMC condition. This indicates that the dyads were rather comparable regarding their

Spanish proficiency. Given that our data were collected in Southern California, which is a highly multilingual environment (e.g., Driever \& Bagheri, 2018; Rumbaut \& Massey, 2013), we assessed participants' language dominance using The Bilingual Language Profile (BLP) questionnaire (Birdsong et al., 2012) to control for potential differences in language dominance due to knowledge of another language(s). The BLP questionnaire elicits participants' information with regards to language history, language use (Spanish, English, other languages), language proficiency in English and Spanish as well as language attitudes through an online Google application. A positive language dominance index score in participants' BLP indicates English dominance, whereas a negative language dominance index score indicates Spanish dominance. A language dominance index score close to zero indicates more balanced bilingualism between Spanish and English. Based on the whole group average of $123.1(S D=28.2)$, our participants were overall more English dominant. Further, the mean language dominance index scores for the AudSCMC $(M=129.1, S D=$ 26.6), VidSCMC $(M=119.2, S D=29.2)$ and TxtSCMC $(M=125.8, S D=27.5)$ conditions 
were not significantly different. This indicates that our groups did not differ according to language dominance. In sum, based on EIT and BLP scores per each condition, as summarized in Table 1, our dyads did not significantly differ according to their Spanish proficiency levels or language dominance.

Table 1

Summary of Group Information

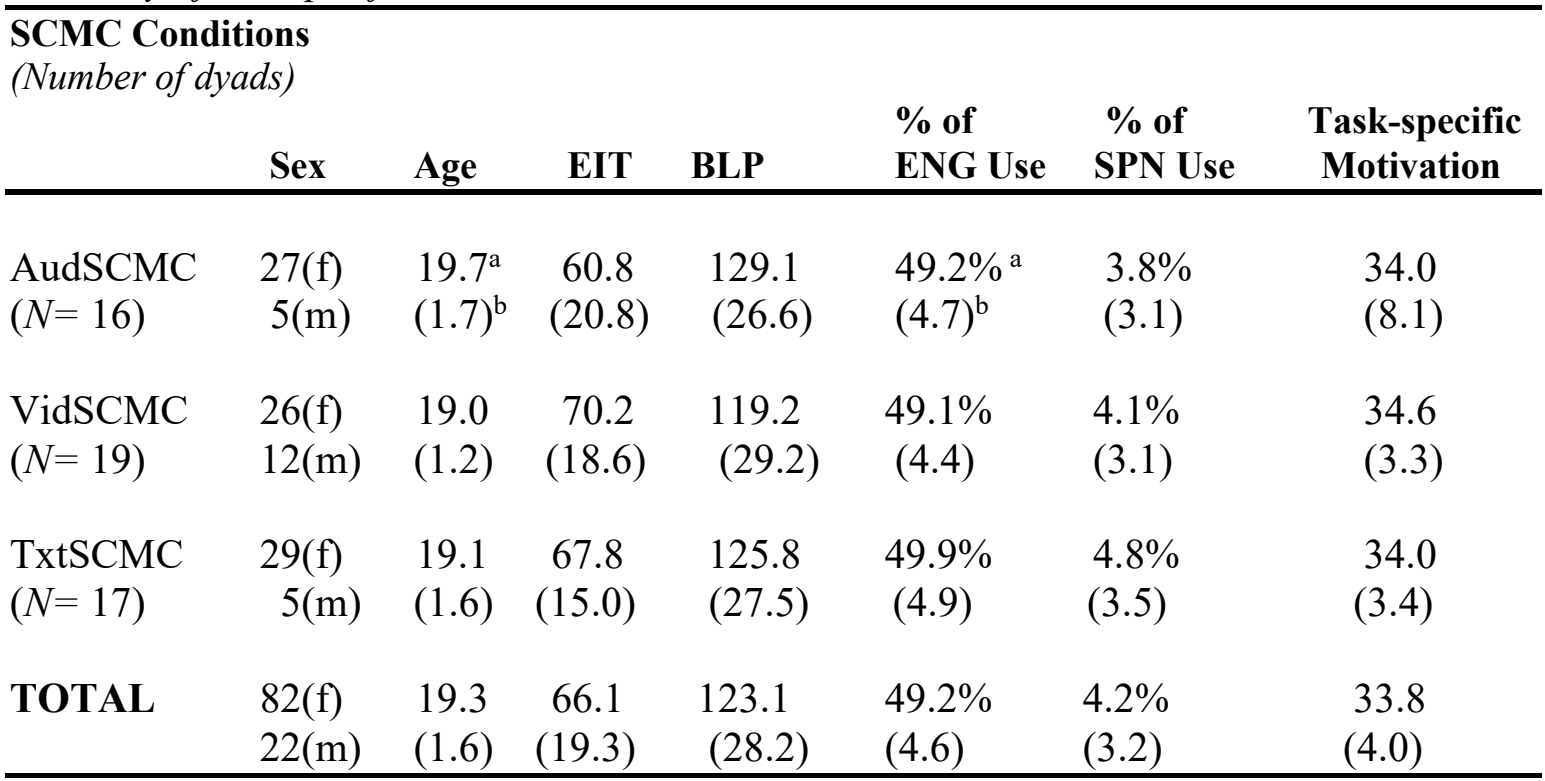

Note. $(\mathrm{f})=$ female,$(\mathrm{m})=$ male; EIT $=$ Elicited Imitated Task; BLP $=$ Bilingual Language Profile; $\mathrm{ENG}=$ English, SPN $=$ Spanish; ${ }^{\mathrm{a}}=$ mean, ${ }^{\mathrm{b}}=$ standard deviation

\section{Materials}

In the current study, our dyads interacted to complete a decision-making/writing real-world task, which was first used in Torres and Cung (2019). For this task, participants had to play the role of business consultants who needed to recommend the hiring of an individual for a well-known Spanish telephone company (i.e., Movistar). Each participant had a list of four applicants, and for each applicant, there was information about name, age, years of experience in the field, position in a former company, desired salary, two of the applicants' best qualities, applicants' overall evaluation from a previous employer and a brief memo from human resources. First, participants had to individually look at the profiles for three minutes and make their own decision as to whom they would recommend for hire. Second, participants were instructed to interact in Spanish to reach an agreement with their partner on whom they would select for the position. Third, once a decision was made, the pairs were instructed to collaborate on writing a formal business letter in Spanish to the CEO of the company justifying their decision. To ensure that both learners collaborated, they were asked to write the exact same letter on their own word document on their computers.

Following task completion, participants were administered a debriefing questionnaire that tapped into their task-specific motivation as well as their perceptions of how helpful their partners had been during task execution. Task-specific motivation has been studied since it can affect the amount of interaction (Dörnyei \& Kormos, 2000) as 
well as the processes by which students control and appraise their actions so that they can successfully carry out a writing task (Yanguas, 2011). The Likert-scale questionnaire used in the current study has been adopted in previous studies (Torres \& Serafini, 2016). Our results revealed that the AudSCMC $(M=34.0, S D=8.1)$, VidSCMC $(M=34.6, S D=3.3)$ and TxtSCMC $(M=34.0, S D=3.4)$ groups did not significantly differ with regards to their task-specific motivation. Therefore, any interaction patterns observed are not attributed to differences in task-specific motivation.

\section{Procedure}

Once participants gave consent to participate in the study, they completed two sessions. For the first session, participants completed the Elicited Imitation Task and the Bilingual Language Profile questionnaire during class time in a language laboratory. For the second session, participants were paired and randomly assigned to one of the three interaction groups --- AudSCMC, VidSCMC and TxtSCMC. During this session, participants were placed in different rooms with a computer laptop and a set of headphones with a microphone to complete the decision-making/writing task. All three groups used Skype to interact and carry out the task. The interactions from the AudSCMC and VidSCMC groups were recorded using Ecamm and Audacity, and the written interactions from the TxtSCMC group were copied into word documents from the Skype chat box. All recordings and word documents were saved for later transcription, coding, and analysis.

\section{Coding Procedure}

The datasets in the AudSCMC and VidSCMC groups were first transcribed so that transcriptions for all three groups could be coded. First, LREs were identified following a well-established definition: any part of the interaction in which participants were engaged with language issues (i.e., metatalk) to address questions (Swain \& Lapkin, 1995; Williams, 1999). Following Storch (2008), LREs were coded according to their focus (grammatical, lexis, mechanics) and resolution (correct, incorrect, not resolved). Further, following Fernández Dobao (2014), we coded the LREs for levels of engagement (elaborate, moderate, limited, non-interactive). Both researchers coded and discussed all the LREs until reaching a 100\% agreement of the coding categories. In Tables 2, 3 and 4, we briefly define every LRE type and provide an example from our dataset. 


\section{Table 2}

Coding Procedure for LRE Focus

\section{LRE focus}

\section{Definition}

Mechanics

Lexis

Grammar
Episodes related to capitalization, spelling and accents

Episodes related to seeking confirmation of a word or the Spanish translation

Episodes related to morphosyntactic issues such as gender/number nounadjective agreement and verb tense and mood.

\section{Example}

A: Será una buena adicion a nuestra compañía. She will be a good addition to our company. B: ¿Y un acento en la "i", no? And an accent on the " $i$ "?

A: Sí. Yes.

A: um uh, lo siento um hmm ¿cómo se dice maybe? I'm sorry, how do you say "maybe?"

B: quizás. Maybe.

A: Bien, por el eval... Good, for the eval...

B: ¿Es el o la? Is it 'the' (masculine) or 'the' (feminine)?

A: Es la porque la profesora dije en viernes a mí que más tiempo cuando una palabra es -ción, es femenina. It is 'the' (feminine) because the professor said on Friday that most times when the word is -cion it is feminine.

Note. LRE $=$ Language related episode. 


\section{Table 3}

Coding Procedure for LRE Resolution

\section{LRE resolution}

\section{Definition}

Correct

Incorrect

Not resolved
Episodes in which dyads correctly addressed a LRE

Episodes in which dyads incorrectly addressed a LRE

Episodes in which dyads do not address a LRE

\section{Example}

A: Um.. por la evaluación de trabajo ella recibe o recib-. Um, for the work evaluation she received a (not sure of the verb form).

B: rec-. rec- (not sure about verb form).

A: ¿Recibí? I received?

B: Recibió porque es tercera persona. She received because it's third person.

A: Oh sí sí sí, sí recibió diez, diez por diez sí? Oh yes, yes, she received a ten, ten out of ten, right?

A: Ohh trabajar por por Movistar para muchos años. Sí. Ohh work for for Movistar for many years.

B: Trabajar para Movistar. To work for Movistar.

A: Pienso que es por. I think it's 'por' (instead of 'para' which is another word for 'for').

B: ¿Por? 'Por?' (for)

A: ¿Por Movistar? ¿Sí? For Movistar? Yes?

B: Umm sí. Yes.

A: Para muchas razones que... For many reasons that... B: ¿Muchas o muchos? Many (masculine) or many (feminine). A: Umm no sé. I don't know.

Note. LRE $=$ Language related episode. 
Table 4

Coding Procedure for LRE Levels of Engagement

\section{LRE levels of engagement}

\section{Definition}

Episodes in which dyads provide A: ¿Obtener? ¿Obtenía? ¿Cómo se evaluation or explanations and scaffold each other.

\section{Example}

dice obtener en el pasado? To get,

S/he used to get? How do you say

to get in the past?

B: ¿Obtener? To obtain?

A: ¿Obtuvi-? ¿Obtuve? ¿Obtuvo? I

got? $\mathrm{S} /$ he got?

B: ¿Obtuvio? S/he got?

A: Tener en el pretérito, ¿sí? Porque ella no trabajó acá, ¿allí? To have in the preterite, right? Because she didn't work here, there?

B: Uh, ¿qué? Uh, what?

A: ¿También ella obtuvo? Porque quiero decir tener en el pretérito porque ella no es, está en el puesto previo. She also go? Because I mean to say to have in the preterite because she is not, she is not in her previous job.

A: Ok, sí. Yes.

B: ¿So es obtuvo or obtuve? So is it she got or I got?

A: Creo que obtuvo. I think it's she got.

Moderate

Episodes in which dyads provide A: ¿Una gerente o un gerente? A alternatives without any explanation or justification. (masculine). manager (feminine) or a manager

B: Una, una gerente. A manager (feminine).

Limited

Episodes in which one participant A: ¿Cómo se escribe posición? How proposes a solution and the other do you write position?

repeats it or responds without B: P-o-s-i-c-i-o con acento i-n. adding information or questioning. $P-o-s-i-c-i-o$ with an accent $i-n$. A: ok.

Non-interactive

Episodes in which only one participant was involved in the discussion. A: ¿Buena porque es evaluación?
Good (feminine) because it is
Evaluation?
A: ¿Buena o bueno? Good (feminine)
or good (masculine)?
A: ¿Buena? Good (feminine)?
A: Porque es evaluación. Because
it's evaluation.

Note. LRE $=$ Language related episode. 


\section{Results}

Prior to addressing the two research questions of the current study, it is important to note our statistical procedure reasoning for analyzing our data. We first ran an analysis to explore whether our data met the assumptions to run a parametric test such as multivariate analysis of variance (MANOVA) given the number of dependent variables. However, a Shapiro-Wilk multivariate normality test revealed a significant result $(p<0.01)$, which indicates a violation of multivariate normality. That is, the scores obtained in the study are not normally distributed (Field, 2009). As such, we opted for the non-parametric KruskallWallis test to run our analyses along with a Dwass-Steel-Critchlow-Flinger post-hoc analysis because it controls for family-wise error rates, and thereby, avoiding inflating Type I error.

In the current study, the first research question posited whether SCMC mode (video, audio, text) had an effect on the quantity, focus and resolution of LREs during taskbased peer interaction. Table 5 displays the descriptive statistics (mean, standard deviation, minimum and maximum scores) for quantity, focus and resolution of LREs. With regards to quantity of LREs, dyads in the VidSCMC condition had the greatest mean score $(M=$ 9.32, $S D=7.4, \operatorname{Max}=33, \mathrm{Min}=2)$ in comparison to the AudSCMC $(M=6.88, S D=4.8$, $M a x=14, \operatorname{Min}=0)$ and TxtSCMC $(M=2.71, S D=1.8, \operatorname{Max}=7, \operatorname{Min}=0)$ conditions. In examining dyads' linguistic focus during LREs, we found that the VidSCMC condition triggered on average a greater number of LREs related to mechanics $(M=2.11, S D=2.4$, $\operatorname{Max}=7, \operatorname{Min}=0)$ followed by the AudSCMC $(M=1.69, S D=2.1, \operatorname{Max}=7, \operatorname{Min}=0)$ and $\operatorname{TxtSCMC}(M=0.29, S D=0.5, M a x=0, M i n=2)$ groups. For lexis LREs, the participants in the AudSCMC condition had a greater mean score $(M=3.06, S D=2.5$, Max $=8$, Min $=$ $0)$ than the VidSMC $(M=2.11, S D=2.3, \operatorname{Max}=7, \operatorname{Min}=0)$ and TextSCMC $(M=1.41, S D=$ 1.5, $\operatorname{Max}=6, \operatorname{Min}=0$ ) conditions. Likewise, the AudSCMC condition had the greatest mean score for grammar LREs $(M=2.00, S D=1.8, \operatorname{Max}=5, \operatorname{Min}=0)$, and then the $\operatorname{VidSCMC}(M=1.32, S D=0.6, \operatorname{Max}=5, \operatorname{Min}=0)$ and $\operatorname{TxtSCMC}(M=0.82, S D=0.6$, $\operatorname{Max}=2$, Min $=0$ ) conditions. Concerning LRE resolutions, the dyads in the AudSCMC condition correctly resolved on average more LREs $(M=4.81, S D=3.6$, Max $=11$, Min= $0)$ than the other two conditions. The mean score of dyads in the VidSCMC group $(M=$ 4.05, $S D=3.8, \operatorname{Max}=4$, Min=0) was close to the AudSCMC group, but the TxtSCMC group's mean score for correctly resolved LREs was lower $(M=1.59, S D=1.5, \operatorname{Max}=6$, Min=0). The dyads in the TxtSCMC group had the highest mean score for incorrectly addressed LREs $(M=1.00, S D=1.3, \operatorname{Max}=2, \operatorname{Min}=0)$ followed by the AudSCMC $(M=$ $0.87, S D=1.2, \operatorname{Max}=4, \operatorname{Min}=0)$ and VidSCMC $(M=0.47, S D=0.7, \operatorname{Max}=4, \operatorname{Min}=0)$ groups. On average, most LREs were not resolved by peers in the AudSCMC condition $(M=1.19, S D=1.6, \operatorname{Max}=6, \operatorname{Min}=0)$, but VidSCMC $(M=0.63, S D=0.8$, Max $=3$, Min= $0)$ and $\operatorname{TxtSCMC}(M=0.23, S D=0.5, M a x=2, M i n=0)$ conditions had lower average scores of not resolved LREs.

Our first Kruskal-Wallis analysis revealed that SCMC mode significantly affects the quantity of LREs produced during task-based peer interaction, $H(2)=11.91, p<0.01$. Post-hoc Dwass-Steel-Critchlow-Fligner pairwise comparisons demonstrated that the AudSCMC and VidSCMC groups significantly produced more LREs than the TxtSCMC group, but no differences between AudSCMC and VidSCMC groups. As far as LRE focus, the groups significantly differed with regards to addressing mechanics, $H(2)=8.93, p=$ 
0.01, with AudSCMC and VidSCMC conditions addressing mechanics in a similar fashion, but both conditions significantly differed from the TxtSCMC condition. A significant finding was also found for correct LRE resolutions, $H(2)=6.98, p=0.03$, with a post-hoc analysis revealing that the significant finding was due to the dyads in the AudSCMC condition correctly addressing LREs more times than dyads in the TxtSCMC condition. 
Table 5

Descriptive Statistics for Quantity, Focus and Resolution of LREs

\begin{tabular}{|c|c|c|c|c|c|c|c|}
\hline \multirow[t]{2}{*}{$\begin{array}{l}\text { SCMC condition } \\
\text { (Number of dyads) }\end{array}$} & \multirow{2}{*}{$\begin{array}{l}\text { LRE Quantity } \\
\text { Total** }\end{array}$} & \multicolumn{3}{|l|}{ LRE Focus } & \multicolumn{3}{|c|}{ LRE Resolution } \\
\hline & & Mechanics* & Lexis & Grammar & Correct* & Incorrect & Not resolved \\
\hline $\begin{array}{l}\text { AudSCMC } \\
(N=16)\end{array}$ & $\begin{array}{l}6.88^{\mathrm{a}}(4.8)^{\mathrm{b}} \\
{\left[0^{\mathrm{c}}, 14^{\mathrm{d}}\right]}\end{array}$ & $\begin{array}{l}1.69(2.1) \\
{[0,7]}\end{array}$ & $\begin{array}{l}3.06(2.5) \\
{[0,8]}\end{array}$ & $\begin{array}{l}2.00(1.8) \\
{[0,5]}\end{array}$ & $\begin{array}{l}4.81(3.6) \\
{[0,11]}\end{array}$ & $\begin{array}{l}0.87(1.2) \\
{[0,4]}\end{array}$ & $\begin{array}{l}1.19(1.6) \\
{[0,6]}\end{array}$ \\
\hline $\begin{array}{l}\text { VidSCMC } \\
(N=19)\end{array}$ & $\begin{array}{l}9.32(7.4) \\
{[2,33]}\end{array}$ & $\begin{array}{l}2.11(2.4) \\
{[0,7]}\end{array}$ & $\begin{array}{l}2.11(2.3) \\
{[0,7]}\end{array}$ & $\begin{array}{l}1.32(0.6) \\
{[0,5]}\end{array}$ & $\begin{array}{l}4.05(3.8) \\
{[0,11]}\end{array}$ & $\begin{array}{l}0.47(0.7) \\
{[0,4]}\end{array}$ & $\begin{array}{l}0.63(0.8) \\
{[0,3]}\end{array}$ \\
\hline $\begin{array}{l}\text { TxtSCMC } \\
(N=17)\end{array}$ & $\begin{array}{l}2.71(1.8) \\
{[0,7]}\end{array}$ & $\begin{array}{l}0.29(0.5) \\
{[0,2]}\end{array}$ & $\begin{array}{l}1.41(1.5) \\
{[0,6]}\end{array}$ & $\begin{array}{l}0.82(0.6) \\
{[0,2]}\end{array}$ & $\begin{array}{l}1.59(1.5) \\
{[0,6]}\end{array}$ & $\begin{array}{l}1.00(1.3) \\
{[0,2]}\end{array}$ & $\begin{array}{l}0.23(0.5) \\
{[0,2]}\end{array}$ \\
\hline
\end{tabular}


The second research question was concerned with the effects of SCMC mode on LRE levels of engagement. Table 6 summarizes the descriptive statistics for each group's production of LRE levels of engagement. To begin, the AudSCMC condition led to a higher average of elaborate LREs $(M=0.94, S D=1.3, \operatorname{Max}=4, \operatorname{Min}=0)$ followed by $\operatorname{TxtSCMC}(M=0.47, S D=0.7, \operatorname{Max}=2, \operatorname{Min}=0)$ and $\operatorname{VidSCMC}(M=0.16, S D=0.7$, Max $=2$, Min $=0)$. As far as moderate LREs, the AudSCMC group also had the greatest average $(M=1.13, S D=1.0 ; \operatorname{Max}=3$, Min $=0)$, with lesser and close averages between the $\operatorname{VidSCMC~}(M=0.89, S D=1.1, \operatorname{Max}=5, \operatorname{Min}=0)$ and TxtSCMC $(M=0.82, S D=1.3$, $\operatorname{Max}=5$, Min=0) conditions. The VidSCMC group had the highest average for engaging with limited LREs $(M=4.47, S D=4.2, \operatorname{Max}=14$, Min=0) though the AudSCMC condition's average was close $(M=4.13, S D=3.4, \operatorname{Max}=11, \operatorname{Min}=0)$. The TxtSCMC group displayed the smallest average in producing limited LREs $(M=1.18, S D=1.0$, $\operatorname{Max}=0$, Min $=0$ ). Finally, the AudSCMC condition had a higher average of noninteractive LREs $(M=0.68, S D=1.1, \operatorname{Max}=4, \operatorname{Min}=0)$ followed by the $\operatorname{VidSCMC}(M=$ $0.31, S D=0.4, \operatorname{Max}=4, \operatorname{Min}=0)$ and TxtSCMC $(M=0.11, S D=0.4, \operatorname{Max}=2, \operatorname{Min}=0)$ conditions.

Kruskal-Wallis analyses demonstrated a significant finding for limited LREs, $H(2)$ $=7.12, p=0.02$, and a marginal significant finding for elaborate LREs, $H(2)=5.39, p=$ 0.06 . No significant differences were found for moderate, $H(2)=2.09, p=0.35$, or noninteractive LREs, $H(2)=4.77, p=0.10$. To gain insight into the findings, we also ran posthoc analyses with the Dwass-Steel-Critchlow-Figner pairwise comparison test, and we found that the participants in the AudSCMC condition significantly engaged more with limited LREs in comparison to the TxtSCMC group. Further, the marginal significant result was due to a trend in which the AudSCMC condition engaged more with elaborate LREs than the VidSCMC condition.

Table 7 summarizes the significant post-hoc findings of the study. First, the findings revealed that the AudSCMC and VidSCMC conditions led pairs to significantly trigger a higher number of LREs during task-based interaction. Second, we also found that both AudSCMC and VidSCMC groups significantly addressed issues related to mechanics more frequently than the TxtSCMC group. Third, in comparison to the TxtSCMC group, AudSCMC dyads significantly resolved LREs more correctly. Fourth, with regards to LRE levels of engagement, the dyads in the AudSCMC group significantly engaged more with limited LREs than the TxtSCMC group. Furthermore, a trend emerged in which the AudSCMC participants deliberated more elaborate LREs vis-à-vis the VidSCMC condition. 
Table 6

Descriptive Statistics for LRE Levels of Engagement

SCMC condition

(Number of dyads)

\section{LRE Levels of Engagement}

\begin{tabular}{|c|c|c|c|c|}
\hline & Elaborate $^{\dagger}$ & Moderate & Limited* & Non-interactive \\
\hline $\begin{array}{l}\text { AudSCMC } \\
(N=16)\end{array}$ & $\begin{array}{l}0.94^{\mathrm{a}}(1.3)^{\mathrm{b}} \\
{\left[0^{\mathrm{c}}, 4^{\mathrm{d}}\right]}\end{array}$ & $\begin{array}{l}1.13(1.0) \\
{[0,3]}\end{array}$ & $\begin{array}{l}4.13(3.4) \\
{[0,11]}\end{array}$ & $\begin{array}{l}0.68(1.1) \\
{[0,4]}\end{array}$ \\
\hline $\begin{array}{l}\text { VidSCMC } \\
(N=19)\end{array}$ & $\begin{array}{l}0.16(0.7) \\
{[0,2]}\end{array}$ & $\begin{array}{l}0.89(1.1) \\
{[0,5]}\end{array}$ & $\begin{array}{l}4.47(4.2) \\
{[0,14]}\end{array}$ & $\begin{array}{l}0.31(0.4) \\
{[0,1]}\end{array}$ \\
\hline $\begin{array}{l}\text { TxtSCMC } \\
(N=17)\end{array}$ & $\begin{array}{l}0.47(0.7) \\
{[0,2]}\end{array}$ & $\begin{array}{l}0.82(1.3) \\
{[0,5]}\end{array}$ & $\begin{array}{l}1.18(1.0) \\
{[0,4]}\end{array}$ & $\begin{array}{l}0.11(0.4) \\
{[0,2]}\end{array}$ \\
\hline
\end{tabular}

Note. SCMC = synchronous computer-mediated communication; LRE = Language related episode;

${ }^{\mathrm{a}}=$ mean score $;{ }^{\mathrm{b}}=$ standard deviation; $^{\mathrm{c}}=$ minimum score; ${ }^{\mathrm{d}}=$ maximum score; $\uparrow=p=0.06, *=p$

$<0.05$.

Table 7

Summary of (Marginal) Significant Post-hoc Results

\begin{tabular}{ll}
\hline LRE Measures & Results \\
\hline Quantity of LREs & AudSCMC, VidSCMC $>$ TxtSCMC \\
Focus of LREs - Mechanics & AudSCMC, VidSCMC $>$ TxtSCMC \\
Resolution of LREs - Correct & AudSCMC $>$ TxtSCMC \\
Limited LREs & AudSCMC $>$ TxtSCMC \\
Elaborate LREs & AudSCMC $>$ VidSCMC (marginal) \\
\hline
\end{tabular}

Note. LRE = language related episode

\section{Discussion}

Previous studies have begun to document how L2 peer interactions across audio, video, and text SCMC modalities can affect learning opportunities and language development (Jepson, 2005; Sykes, 2005; Yanguas, 2010, 2012; Yanguas and Bergin, 2018). The current study expanded this research strand by investigating whether peer interactions across SCMC conditions had an impact on LRE levels of engagement (i.e., elaborate, moderate, limited, non-interactive) during the execution of a real-world task with a group of L2 Spanish intermediate learners. The theoretical motivation of the study is based on the predictions of the interactionist approach (e.g., Gass \& Mackey, 2020; Mackey et al., 2012) as well as how task conditions can play a significant role in task outcomes (Skehan, 2016). 
Our first research question was concerned with the role of SCMC modalities on the quantity, focus and resolution of LREs during task-based peer interaction. Based on previous literature, we hypothesized a significantly smaller number of LREs for the TxtSCMC group as well as more unresolved LREs for dyads in the AudSCMC condition. We first found that the AudSCMC and VidSCMC groups significantly produced more LREs than the TxtSCMC group. This result replicates previous findings in which fewer LREs were generated in TxtSCMC in comparison with face-to-face conditions with groups of intermediate-level English and advanced-level Spanish learners (Hamano-Bunce, 2011; Rouhshad \& Storch, 2016; Torres \& Cung, 2019). Further, in line with Yanguas and Bergin (2018), no significant differences emerged between the VidSCMC and AudSCMC groups. Therefore, this finding supports the argument that TxtSCMC might not be the ideal mode for L2 learners to generate a high number of LREs, as the written chat log produced during peer interactions may render the need to discuss language forms unnecessary because it grants L2 learners more time to plan their responses and review interaction content (Ziegler, 2015). Our second significant finding revealed that dyads in the AudSCMC condition correctly resolved more LREs than the TxtSCMC group. This finding suggests that task-based peer interaction via audio mode was often more effective in tapping into L2 learners' linguistic knowledge to provide accurate solutions to languagerelated questions.

With regards to LRE focus, another relevant finding was that the AudSCMC and VidSCMC groups significantly addressed more LREs focused on mechanics (e.g., spelling, accent placement) than the TxtSCMC group. This finding can be attributed to the differences between the written task (i.e., business letter) and interaction modes. Unlike the TxtSCMC condition in which peers wrote out their sentences and phrases in the Skype chat window, the mismatch between the written task and the AudSCMC and VidSCMC modes required those dyads to engage more in addressing mechanics because they needed to put into written form their ideas produced during spoken communication. This finding contrasts with Torres and Cung (2019) who found no significant differences with regards to spelling and accent placement between the TxtSCMC and face-to-face conditions using the same decision-making/writing task in Spanish. Torres and Cung (2019) and the current study differed in the proficiency level of the participants. That is, the participants in Torres and Cung (2019) were advanced learners (both L2 and heritage language learners) enrolled in advanced content courses who had taken specialized Spanish writing courses, whereas the participants in the current study were all L2 learners enrolled in intermediate-level Spanish courses. As such, given that mechanics is an inherent feature of written language as well as the fact that participants had less L2 experience, peer interactions in AudSCMC and VidSCMC prompted dyads to address more often spelling and accent placement issues to compose formal business letters to the CEO of the company, which required a professional register of Spanish.

The second research question posited whether SCMC mode affected L2 learners' levels of engagement (elaborate, moderate, limited, non-interactive) during LRE deliberations. First, our findings revealed that the AudSCMC group significantly produced more limited LREs than the TxtSCMC group. That is, dyads in the AudSCMC condition addressed their LREs more often by repeating their partner's solution or just making comments (e.g., ok) that did not add or question the proposed solution in comparison to the TxtSCMC dyads. Second, a marginal significance $(p=0.06)$ showed that the L2 learners in 
the AudSCMC condition addressed more elaborate LREs than those in the VidSCMC group. Though not a significant finding, the results showed a trend in which dyads in AudSCMC dyads were more likely to engage in explanations and substantive discussion regarding their LREs than the VidSCMC dyads. Further, in examining participants' perceptions of their partner's contribution to the task execution process, we found that $65 \%$ of comments from participants in the AudSCMC condition were related to how their partners helped with the lexical and grammatical encoding of ideas to write in the business letters (e.g., "We worked on spelling and making sure our verb conjugations were correct and improved transitions."). Conversely, only $32 \%$ of the comments were about lexical and grammatical issues in the VidSCMC condition. If participants' perceptions of their partner's contribution to the task are an accurate reflection of the underlying interactive process, a possible explanation for this marginal result could be that the dyads in the AudSCMC condition may have addressed more lexical and grammatical LREs, but this is a trend that must be confirmed with future research.

Regarding LRE levels of engagement, thus, our study shows a novel and relevant finding; namely, task-based peer interactions in the AudSCMC condition led to more levels of engagement during LREs. In contrast to Rouhshad and Storch (2016) who found significantly more limited engagement during LREs in their TxtSCMC group, we found that our TxtSCMC group had the lowest average (Table 6). However, the current study differed from Rouhshad and Storch (2016) in that they compared their TxtSCMC group to a face-to-face condition. This implies that such peer interaction outcome may not hold true when comparing TxtSCMC to oral SCMC modalities. More studies are needed to ascertain whether these differences remain constant across oral modes (face-to-face vs. SCMC) to see whether and how technology could play a role in L2 learners' engagement with LREs. Importantly, however, in line with previous research, we found that it is the L2 learners in the AudSCMC condition that exhibited a different proportion of interactional moves resulting from their peer interactions, as evidenced by significantly higher instances of negotiation of meaning found in other studies (Jepson, 2005; Yanguas, 2010, 2012). This pattern of behaviour also emerged with a different group of L2 learners, task type as well as interactional moves in the current study. More specifically, we found that this difference in proportion of interactional moves can be extended to those that also involve levels of engagement during LREs.

Therefore, due to this pattern of peer interaction behaviour, it merits exploring the nature of the AudSCMC condition that can potentially contribute to L2 learners' seemingly greater production of certain interactional moves. Yanguas (2012) made the key distinction that participants in the AudSCMC condition do not have access to visual cues that can provide extralinguistic information that may facilitate oral interaction the way that the VidSCMC condition does. In fact, studies have shown that L2 learners benefit from visual cues to achieve greater listening comprehension (e.g., Sueyoshi \& Hardison, 2005), and exposure to multimodal L2 input (i.e., visual and audio) seems to lead to greater learning gains (e.g., Peters \& Muñoz, 2020). The question that remains is how the lack of visual cues in the AudSCMC task condition placed differential demands on the L2 learners that pushed them to a greater tendency to address LREs, whether limited or elaborate, in comparison to the text and video SCMC modes. On the one hand, it is well established that humans process visual and auditory information through different channels (Mayer, 2005), which could be a key factor in interpreting the differences between the TxtSCMC and 
AudSCMC groups. On the other hand, it appears that the visual cues in the VidSCMC group compensated peer interaction dynamics with nonverbal communication that may have altered learners' engagement with LREs.

As such, the dyads in the AudSCMC condition were relying exclusively on linguistic information as well as their auditory receptors to complete the task. Arguably, then, the AudSCMC condition presented certain constraints to intermediate-level L2 learners that bore consequences into how they tackled language forms during task-based peer interaction. One consequence of this condition, particularly with regards to limited LREs vis-à-vis the TxtSCMC group, could be that since the dyads did not see each other nor did they have access to a written chat box to simply copy language forms produced by their partner, it required them to acknowledge and confirm their partner's solutions to LREs more frequently (e.g., ok) to carry on with their interaction. Another consequence due to the elimination of visual cues is that the AudSCMC condition most likely forced dyads to recruit more cognitive resources during their deliberation of LREs. This recruitment of cognitive resources may not have occurred in the same way with the TxtSCMC group because L2 learners had more time to plan their written language production. Potentially, then, engaging more cognitive resources in audio mode led to dyads' inclination to address LREs more fully with explanations and scaffolding than the dyads in other conditions.

While more research is needed to confirm the observations in this study, the findings have implications for pedagogical practices within a TBLT framework. In addressing language teaching practices in a virtual environment, the findings suggest that designing collaborative tasks for an audio mode can be beneficial for learners to engage with language forms in a more substantive way. The design of tasks for audio mode also aligns with real-world tasks, especially as individuals communicate to send and receive audio messages through mobile devices. As such, instructors can design relevant collaborative tasks that allow learners to solve problems and reach communicative goals through AudSCMC. For example, for beginning-level courses, a collaborative task in AudSCMC can be producing a grocery shopping list of foods to buy for a dinner party. The students need to read the dietary restrictions of the people attending the dinner party, and based on this information, they need to decide what to buy at the supermarket. This task can be accomplished by students sending each other voice messages to reach the communicative task goal.

\section{Conclusion}

The current study took a cognitive-interactionist approach to task-based peer interaction (e.g., Mackey et al., 2012) and provided empirical support for the claim that task conditions often determine L2 learners' task outcomes (Skehan, 2016). We explored whether the affordances of technology to create audio, video, and text SCMC task conditions can affect intermediate-level Spanish L2 dyads' levels of engagement (e.g., elaborate, limited) with LREs during an unfocused real-world task. This is critical given that evidence exists that more elaborate levels of engagement with language forms during LREs lead to greater retention of those forms (Storch, 2008). The main findings revealed that the audio SCMC task condition was more conducive to a significantly greater number of limited LREs as well as a trend to more elaborate LREs vis-à vis the text and audio 
SCMC task conditions, respectively. These results were attributed to participants' exclusive reliance on their auditory receptors and linguistic information that most likely shaped their cognitive behaviour during task-based peer interaction.

\section{Future Research}

In addition to the need to replicate these findings with populations with different proficiency levels, languages, and learner profiles (e.g., heritage language learners) as well as task types, we propose three areas for future research. First, one of the limitations of the current study is that we did not collect data on L2 learners' perceptions of their interactions in these SCMC conditions to better document their cognitive behaviour. Therefore, using mixed methods, future research ought to provide evidence for the cognitive behaviour of L2 learners in each of these SCMC conditions. This can consist of conducting stimulated recall sessions to gather participants' insights of screen and audio recordings during task completion along with other triangulating measures such as questionnaires or eye-tracking. Researchers can examine whether participants' verbalizations of their task performance reflect any difficulties in accomplishing the task goal. Further, this can include their noticing and depth of processing of linguistic forms during their engagement with interactional moves (e.g., LREs) across SCMC conditions. These data will help clarify how the differential demands of the distinct SCMC task conditions have an impact on task outcomes. Second, while consensus exists that interaction leads to L2 development, a critical area that deserves more attention is linking L2 learners' engagement with LREs across SCMC modalities with long-term retention of the linguistic forms that were discussed during LRE deliberations. If $\mathrm{L} 2$ learners are indeed recruiting more cognitive resources due to the demands of an audio SCMC environment, we would predict that L2 peer interactions in audio mode would enjoy greater learning gains. However, more research is needed to provide robust evidence for the learning benefits that can result from elaborate engagements during task-based interaction. Third, given the availability of multimodal platforms available to instructors and students (e.g., zoom, google meet), another line of research is to examine how L2 learners completing a task in a mostly audio mode make use of the text chat mode during task-based interaction. In other words, we need more insight into how a combination of modes support learners' ability to meet the task outcome with regards to LREs and other interactional moves. And, critically, during what instances do learners seek support from another mode (e.g., text), especially when completing a task in audio mode.

Correspondence should be addressed to Julio Torres.

Email: torresju@uci.edu

\section{References}

Abadikhah, S. (2011). Investigating language-related episodes during mechanical and meaningful output activities. International Journal of English Linguistics, 1(2), 281-294.

Birdsong, D. (2006). Dominance, proficiency, and second language grammatical processing. Applied Psycholinguistics, 27, 46- 49. 
Birdsong, D., Gertken, L. M., \& Amengual, M. (2012). Bilingual language profile: An easy-to-use instrument to assess bilingualism. COERLL, University of Texas at Austin. https://sites.la.utexas.edu/bilingual/.

Blake, R. J. (2000). Computer mediated communication: A window of L2 Spanish interlanguage. Language Learning \& Technology, 4, 111-125.

Blake, R. J., \& Guillén, G. A. (2020). Brave new digital classroom: Technology and foreign language learning. Georgetown University Press.

Bowden, H. W. (2016). Assessing second-language oral proficiency for research: The Spanish elicited imitation task. Studies in Second Language Acquisition, 38(4), 647675.

Dörnyei, Z., \& Kormos, J. (2000). The role of individual and social variables in oral task performance. Language Teaching Research, 4, 275-300.

Ellis, R. (2018). Reflections on task-based language teaching. Multilingual Matters.

Ellis, R., \& Shintani, N. (2014). Exploring language pedagogy through second language acquisition research. Routledge Press.

Elola, I., \& Oskoz, A. (2017). Writing with 21st century social tools in the L2 classroom: New literacies, genres, and writing practices. Journal of Second Language Writing, $36,52-60$.

Fernández-Dobao, A. (2014). Attention to form in collaborative writing tasks: Comparing pair and small group interaction. Canadian Modern Language Review, 70(2), 158187.

Fernández-Dobao, A. (2016). Peer interaction and learning. In M. Sato \& S. Ballinger (Eds.), Peer Interaction and Second Language Learning Language Learning \& Language Teaching (pp. 33-61). John Benjamins.

Field, A. (2009). Discovering statistics using SPSS, $3^{\text {rd }}$ edition. SAGE.

Gass, S. M., \& Mackey, A. (2020). Input, interaction, and output in L2 acquisition. In B. VanPatten, G. D. Keating \& S. Wulff (Eds.), Theories in Second Language Acquisition, 3rd edition (pp. 192-222). Routledge Press.

Gilabert, R., Barón, J., \& Llanes, À. (2009). Manipulating cognitive complexity across task types and its impact on learners' interaction during oral performance. IRAL International Review of Applied Linguistics in Language Teaching, 47(3-4), 367395.

González-Lloret, M. (2003). Designing task-based CALL to promote interaction: En busca de esmeraldas. Language Learning \& Technology, 7, 86-104.

González-Lloret, M. (2020). Collaborative tasks for online language teaching. Foreign Language Annals, 53(2), 260-269.

González-Lloret, M., \& Ortega, L. (2014). Towards technology-mediated TBLT. In M. González-Lloret \& L. Ortega (Eds.), Technology-mediated TBLT task-based language teaching (pp. 1-22). John Benjamins.

Hamano-Bunce, D. (2011). Talk or chat? Chatroom and spoken interaction in a language classroom. ELT Journal, 65(4), 426-436.

Hatch, E. M. (1978). Second language acquisition: A book of readings. Newbury House.

Henshaw, F. (2015). Learning outcomes of L2-heritage learner interactions: The proof is in the posttests. Heritage Language Journal, 12, 245-270.

Jepson, K. (2005). Conversations-and negotiated interaction-in text and voice chat rooms. Language Learning \& Technology, 9(3), 79-98. 
Kang, E. Y., Sok, S., \& Han, Z. (2019). Thirty-five years of ISLA on form-focused instruction: A meta-analysis. Language Teaching Research, 23(4), 428-453.

Keck, C., Iberri-Shea, N., Tracy-Ventura, N., \& Wa-Mbaleka, S. (2006). Investigating the empirical link between task-based interaction and acquisition: A meta-analysis. In J. Norris \& L. Ortega (Eds.), Synthesizing research on language learning and teaching (pp. 91-132). John Benjamins.

Kim, Y. (2008). The role of task-induced involvement and learner proficiency in L2 vocabulary acquisition. Language Learning, 58, 285-325.

Kim, Y., \& McDonough, K. (2008). The effect of interlocutor proficiency on the collaborative dialogue between Korean as a second language learners. Language Teaching Research, 12(2), 211-234.

Lai, C., \& Zhao, Y. (2006). Noticing and text-based chat. Language Learning \& Technology, 12, 211-234.

Lee, L. (2001). Online interaction: Negotiation of meaning and strategies used among learners of Spanish. ReCALL, 13(2), 232-244.

Loewen, S., \& Sato, M. Interaction and instructed second language acquisition. Language Teaching, 51(3), 285-329.

Loewen, S., \& Wolff, D. (2016). Peer interaction in F2F and CMC contexts. In M. Sato \& S. Ballinger (Eds.), Peer interaction and second language learning: Pedagogical potential and research agenda (pp. 163-184). John Benjamins.

Long, M. H. (1981). Input, Interaction, And Second-Language Acquisition. Annals of the New York Academy of Sciences, 379, 259-278.

Long, M. H. (1983). Linguistic and conversational adjustments to nonnative speakers. Studies in Second Language Acquisition, 5, 177-193.

Long, M. H. (1996). The role of the linguistic environment in second language acquisition. In W. C. Ritchie \& T. K. Bhatia (Eds.), Handbook of Second Language Acquisition, (pp. 413-468). Academic Press.

Mackey, A., Abbuhl, R., \& Gass, S. M. (2012). Interactionist approach. In S. M. Gass \& A. Mackey (Eds.), The Routledge handbook of second language acquisition (pp. 408452). Routledge Press.

Mackey, A., \& Goo, J. (2007). Interaction research in SLA: A meta-analysis and research synthesis. In A. Mackey (Ed.), Conversational interaction in SLA: A collection of empirical studies (pp. 408-452). Oxford University Press.

Mayer, R. E. (2005). Cognitive theory of multimedia learning. In R. E. Mayer (Ed.), The Cambridge handbook of multimedia learning (pp. 31-48). Cambridge University Press.

Michel, M. C. (2011). Effects of task complexity and interaction on L2 performance. In P. Robinson (Ed.), Second language task complexity task-based language teaching (pp. 141-173). John Benjamins.

Niu, R. (2009). Effect of task-inherent production modes on EFL learners' focus on form. Language Awareness, 18(3-4), 384-402.

Ortega, L. (2000). Understanding syntactic complexity: The measurement of change in the syntax of instructed L2 Spanish learners [Unpublished doctoral dissertation]. University of Hawai'i at Manoa. 
Ortega, L. (2009). Interaction and attention to form in L2 text-based computer-mediated communication. In A. Mackey \& C. Polio (Eds.), Multiple perspectives of interaction (pp. 226-252). Routledge Press.

Peters, E., \& Muñoz, C. (2020). Language learning from multimodal input. Language Learning, 42, 489-497.

Philp, J. (2016). New pathways in researching interaction. In M. Sato \& S. Ballinger (Eds.), Peer interaction and second language learning: Pedagogical potential and research agenda (pp. 377-395). John Benjamins.

Philp, J., Iwashita, N., \& Adams, R. J. (2014). Peer interaction and second language learning. Routledge Press.

Pica, T. (1994). Research on negotiation: What does it reveal about second-language learning conditions, processes, and outcomes? Language Learning, 44(3), 493-527.

Robinson, P. (2011). Second language task complexity researching the cognition hypothesis of language learning and performance. John Benjamins.

Rouhshad, A., \& Storch, N. (2016). A focus on mode: Patterns of interaction in face-toface and computer-mediated contexts. In M. Sato \& S. Ballinger (Eds.), Peer interaction and second language learning: Pedagogical potential and research agenda (pp. 267-290). John Benjamins.

Russell, J., \& Spada, N. (2006). The effectiveness of corrective feedback for the acquisition of L2 grammar: A meta-analysis of the research. In J. M. Norris \& L. Ortega (Eds.), Synthesizing research on language learning and teaching (pp. 133164). John Benjamins.

Sato, M., \& Ballinger, S. (2016). Understanding peer interaction. In M. Sato \& S. Ballinger (Eds.), Peer interaction and second language learning: Pedagogical potential and research agenda (pp. 1-30). John Benjamins.

Sato, M., \& Lyster, R. (2007). Modified output of Japanese EFL learners: Variable effects of interlocutor versus feedback types. In A. Mackey (Ed.), Conversational interaction in SLA: A collection of empirical studies (pp. 123-142). Oxford University Press.

Sauro, S. (2011). SCMC for SLA: A research synthesis. CALICO Journal, 28, 369-391.

Skehan, P. (2009). Modelling second language performance: Integrating complexity, accuracy, fluency, and lexis. Applied Linguistics, 30(4), 510-532.

Skehan, P. (2016). Tasks versus conditions: Two perspectives on task research and their implications for pedagogy. Annual Review of Applied Linguistics, 36, 34-49.

Storch, N. (2002). Patterns of Interaction in ESL Pair Work. Language Learning, 52(1), 119-158.

Storch, N. (2008). Metatalk in a pair work activity: Level of engagement and implications for language development. Language Awareness, 17(2), 95-114.

Sueyoshi, A., \& Hardison, D. M. (2005). The role of gestures and facial cues in second language listening comprehension. Language Learning, 55(4), 661-699.

Swain, M., \& Lapkin, S. (1995). Problems in output and the cognitive processes they generate: A step towards second language learning. Applied Linguistics, 16(3), 371391.

Sykes, J. M. (2005). Synchronous CMC and pragmatic development: Effects of oral and written chat. CALICO Journal, 22(3), 399-431.

Thorne, S. L., \& Reinhardt, J. (2008). Bridging activities, new media literacies, and 
advanced foreign language proficiency. CALICO Journal, 25, 558-572.

Torres, J., \& Cung, B. (2019). A comparison of advanced heritage language learners' peer interaction across modes and pair types. The Modern Language Journal, 103(4), 815-830.

Torres, J., \& Serafini, E. J. (2016). Microevaluating learners' task-specific motivation in a task-based business Spanish course. Hispania, 99(2), 289-304.

Treffers-Daller, J. (2011). Operationalizing and measuring language dominance. International Journal of Bilingualism, 15, 1-17.

Williams, J. (1999). Learner-generated attention to form. Language Learning, 49(4), 583625.

Yanguas, I. (2010). Oral computer-mediated interaction between L2 learners: It's about time! Language Learning \& Technology, 14(3), 72-93.

Yanguas, I. (2011). The dynamic nature motivation during the task: can it be captured? Innovation in Language Learning and Teaching, 5(1), 35-61.

Yanguas, I. (2012). Task-based oral computer-mediated communication and L2 vocabulary acquisition. CALICO Journal, 29(3), 507-531.

Yanguas, I., \& Bergin, (2018). Focus on form in task-based L2 oral computer-mediated communication. Language Learning \& Technology, 22(3), 65-81.

Zheng, B., Yim, S., \& Warschauer, M. (2018). Social media in the writing classroom and beyond. In J. I. Liontas (Ed.), The TESOL Encyclopedia of English Language Teaching (pp. 1-5). John Wiley \& Sons.

Ziegler, N. (2015). Synchronous computer-mediated communication and interaction. Studies in Second Language Acquisition, 38(3), 553-586.

Ziegler, N. (2016). Taking technology to task: Technology-mediated TBLT, performance, and production. Annual Review of Applied Linguistics, 36, 136-163. 